\title{
Hevelopment of a best-practice mineral resource classification system for the De Beers group of companies
}

\author{
by S. Duggan*, A. Grills*, J. Stiefenhofert, and M. Thurstont
}

\section{Synopsis}

The De Beers Group of Companies has operating diamond mines and exploration projects in numerous countries including South Africa, Namibia, Botswana, and Canada. Diamond deposits are often geologically complex and typically characterized by significant variability in terms of grade and other variables. In addition, diamond revenue also needs to be estimated. These issues make evaluation sampling difficult and accurate Mineral Resource estimation problematic. De Beers identified the need for sound Mineral Resource classification that highlighted areas of uncertainty in the Mineral Resource. As a result De Beers has invested considerable time in developing a best-practice Mineral Resource Classification System (MRCS). In 2004 De Beers developed a prototype that identified the five key Mineral Resource criteria of geology, grade, volume, revenue, and density. A set of key questions and associated answers was developed for each criterion and a scoring system introduced. The MRCS prototype was tested on a wide range of De Beers diamond deposits. Critically, this extensive database of deposits allowed the questions, scoring, and priorities to be adjusted until representative and consistent classifications were produced. The MRCS has evolved through time and, more recently, significant changes have been made that include the ability to take cognisance of new data obtained during mining and production performance. The process involves the project geologist completing the five scorecards, which are reviewed internally prior to an independent review and final ratification by a Competent Person (CP). De Beers is of the opinion that the system is leading practice and provides a repeatable and constant depiction of the confidence in the Company's mineral resources.

\section{Keywords}

diamonds, mineral resource classification, geology, grade volume, revenue, density. other mineral deposits, as illustrated in Figure 1. These factors make the accurate estimation of diamond resources challenging and dictate that a significant quantity of optimized sampling is required to minimize risk. It follows that an accurate view of the level of uncertainty in the Mineral Resource estimate is critical in terms of obtaining a representative Mineral Resource classification for diamond deposits. The classification plays a critical role in terms of the status of a diamond deposit in the project delivery pipeline and the associated investment decisions. As a result, De Beers has invested considerable time in devising a best-practice classification methodology and subsequently developing an appropriate software package, the Mineral Resource Classification System (MRCS).

\section{Classification of diamond deposits}

In the authors' experience there are many cases where insufficient diligence is applied to the Mineral Resource classification process relative to the completion of the Mineral Resource estimate. This lack of thoroughness is often related to a poor understanding of the classification categories and/or the ability to interpret the various classification code guidelines. However, the need for an Indicated Mineral Resource in order to conduct a Feasibility Study requires the classification process to be thorough and justifiable. As highlighted in the introduction, the classification of a diamond resource is typically more complex than for other mineral resources for a number of reasons.

\footnotetext{
* Z Star Mineral Resource Consultants (Pty) Ltd, South Africa.

+ De Beers Group Services (Pty) Ltd, South Africa.

(C) The Southern African Institute of Mining and Metallurgy, 2017. ISSN 2225-6253. This paper was first presented at the SAMREC/SAMVAL Companion Volume Conference 'An Industry Standard for Mining Professionals in South Africa', 17-18 May 2016, Emperors Palace, Johannesburg
} 


\section{Development of a best-practice mineral resource classification system}

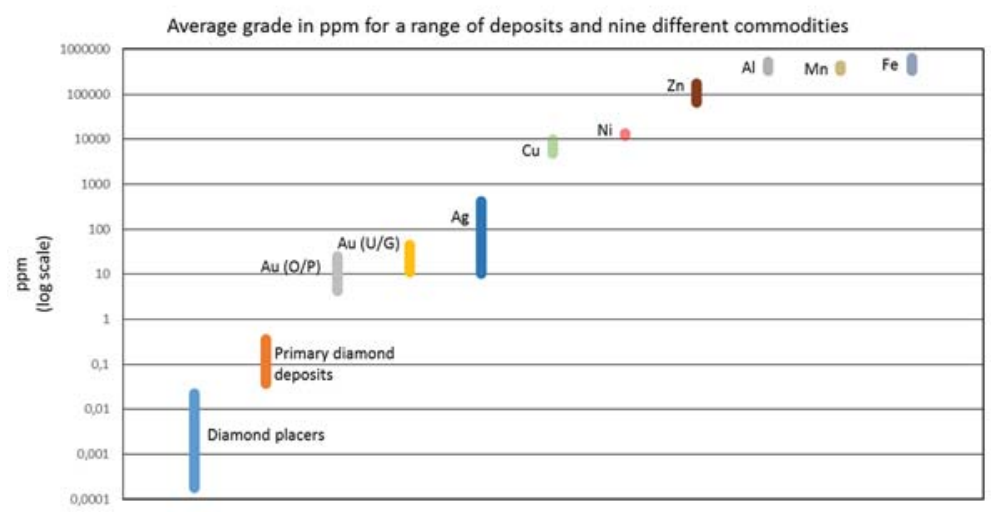

Figure 1-Illustration of grade variation in ppm for different commodities

> In-situ diamond grade can be highly variable within a single rock type and can vary significantly between rock types in the same deposit

> In the kimberlite environment the explosive volcanic nature of the pipes often leads to extensive dilution, which adds to the complexity of the grade estimate

> Diamond deposits are particulate and characterized by extremely low grades, typically less than $1 \mathrm{ppm}$. (Figure 1). This makes representative sampling extremely difficult and expensive. In many cases, due to cost, a move has been made to micro-diamond sampling, i.e. the sampling of a particular portion of the size frequency distribution (SFD) to estimate the diamond grade for the entire SFD

> Diamond revenue is typically estimated from a SFD and an assortment. The assortment provides an average US dollar value per carat per size class based on modelling valuation results. This is combined with the SFD to provide an overall average US dollar per carat estimate. This estimate may be for the entire pipe, or for a particular rock type within the pipe. The accuracy of the assortment, in particular, is often dependent on acquiring a sufficiently representative diamond parcel (e.g. $>5000$ carats)

> Being particulate in nature, diamond resources must be quoted at a defined bottom cut-off, e.g. a nominal square mesh cut-off of $1.15 \mathrm{~mm}$. The grade and bottom cut-off are typically determined by economic studies that optimize these parameters for the resource in question. Should the production plant have a different bottom cut-off (e.g. $1.40 \mathrm{~mm}$ ) or treatment process, e.g. re-crush to a different particle size, Resource to Reserve modifying factors are required.

In 2004, based on the above reasons, De Beers identified the need to develop an appropriate classification methodology (and associated system) to categorize diamond deposits. The methodology had to accommodate three primary requirements:

> To enable mineral resource managers across the De Beers Group to refer to a standard system of classification across all deposit types (kimberlites, placers, and tailings) and thus ensure compatibility across the Group

> To consistently and accurately assess the diamond resource risk
> To undertake a classification compatible and compliant with generally accepted international reporting codes.

\section{Historical classification at De Beers}

The methodology devised for classifying De Beers mineral resources involved the development of prototype scorecards for each of the five key mineral resource variables:

> Geology (the thinking behind the emplacement or deposition model)

> Grade (the data integrity, estimation methodology and process, and validity of results)

> Volume (the constructed 2D or 3D representation of the geological thinking)

> Revenue (the data integrity, SFD and assortment modelling, and validity of results)

> Density (the data integrity, estimation methodology and process, and validity of results).

The process started with the development of the prototype scorecard based on a set of key questions and associated range of answers for each variable. The scoring associated with each question ranged from low for a negative outcome through medium for a partial outcome to high for a positive outcome. The questions in each of the variable scorecards were grouped into sets, e.g. data integrity or estimation methodology, and a priority assigned to the group of questions. The ability to assign priorities to each of the variables (geology, grade etc.) was also introduced as some variables, e.g. grade, were deemed to be more important than others, e.g. density.

Importantly, the prototype scorecard system was tested on a wide range of De Beers diamond deposits, i.e. kimberlites, placers, and tailings mineral resources. Critically, this extensive database of deposits allowed the questions, scoring, and priorities to be adjusted until representative and consistent classifications were being produced.

Once the scorecard methodology had been approved and implemented, the formal classification of all diamond deposits across the De Beers Group of Companies was undertaken by a Mineral Resource Classification Committee (MRCC) in 2004. The committee comprised De Beers specialists representing the mineral resource disciplines of geological modelling, grade and density estimation, and diamond revenue modelling. The committee mechanism assisted in ensuring consistency and compatibility of classification across all 


\section{Development of a best-practice mineral resource classification system}

operations and deposit types; the chairman of the committee was responsible for the final sign-off of a classification.

The classification scorecard can also be used in a proactive sense to analyse the work undertaken on a deposit and identify the risks (areas outstanding) that require addressing prior to attaining a particular confidence level, e.g. Indicated.

\section{Key elements of the current De Beers classification methodology}

The formal classification at De Beers was initially undertaken by the MRCC. Typically, the project geologist or relevant mineral resource manager would present a preliminary scorecard to the MRCC for review. The scorecards would be interrogated and modified during the meeting, if required. At a later stage the MRCC would meet to ratify the scorecard. This process involved checking the classification database to ensure that question scores were compatible with deposits elsewhere in the Group where a similar amount and quality of work had been undertaken. Once ratification was complete the scorecard was signed off by the chairman of the MRCC.

More recently the emphasis has moved towards ownership on the operations with the relevant Competent Person (CP) approving the final classification. However, the current classification process does require a peer review on the operation and, in addition, an independent external review. To this end there are four key steps in the current De Beers classification process:

> An initial classification by the project geologist, i.e. based on the project work undertaken, a series of questions are answered for each of five scorecards and scores assigned

> An on-site peer review by a committee, i.e. answers and scores are amended where applicable according to group consensus

De Beers Mineral Resource Classification Methodology

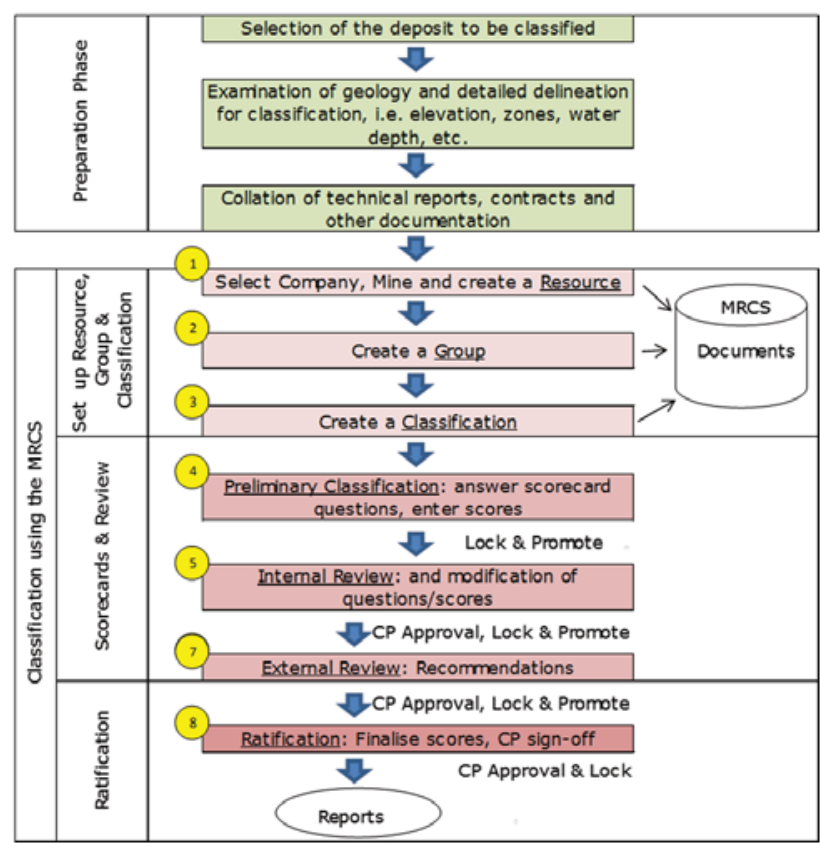

Figure 2-The De Beers mineral resource classification methodology
> An independent external review (i.e. different company and external to the mine) - no changes are implemented, but recommendations are made regarding questions and scores for the CP's consideration

- Finalization by the De Beers-appointed CP (may include the external review's recommended changes if deemed appropriate).

This best-practice approach to mineral resource classification ensures good governance by providing a representative semi-quantitative view on the level of confidence, thus ensuring adherence to the various international reporting guidelines (e.g. SAMREC, JORC, and NI 43-101).

The methodology developed comprises four main processes (Figure 2):

$>$ A preparation phase where the deposit to be classified is defined and information required collated

> A set-up phase which requires the user to select the appropriate De Beers company and operation in the MRCS and create a Resource, group, and classification

> A completion phase where a preliminary scorecard is completed, reviewed by the operation, and finally submitted for external review (i.e. by a different company)

> A final ratification and sign-off by the $\mathrm{CP}$.

In terms of the MRCS a typical classification will require eight steps as illustrated in Figure 2.

\section{Preparing for classification}

One of the most important tasks in the classification process is the subdivision of the deposit prior to completing the scorecards. It is often the case that a portion of the deposit may have a higher sampling density; this may be a higher grade area that was found first or it may simply be the part of the resource that is closer to surface and has been easier to drill. The higher sampling density will typically facilitate a better understanding of the geological model and thus improved definition in the volume model, the interpolation of local block grades and density estimates, and the recovery of more diamonds, resulting in a higher confidence revenue estimate. When an area or volume is delineated for classification it is critical that a similar level of evaluation work has been undertaken on the entire portion. If this is not the case, the questions become problematic as there can be more than one answer to each question. In summary, it is very important that, having taken the geological model into consideration, the deposit is carefully subdivided into portions with reasonably equal levels of evaluation work prior to classification.

\section{Method of scoring}

An individual score is assigned to each of the 84 questions in the scorecards. Within each individual scorecard, e.g. geology, the assigned scores within each group of questions are averaged. These average scores are then added to provide an overall score for the criteria out of a maximum of 100 . The scorecards for the five key criteria are summarized in Table I in terms of the priority assigned to various groups of questions. 


\section{Development of a best-practice mineral resource classification system}

\section{Table I \\ Illustration of the maximum possible score for groups of questions in each scorecard}

\begin{tabular}{|l|c|c|c|c|c|}
\hline \multicolumn{1}{|c|}{ Group } & Geology & Grade & Volume & Revenue & Density \\
\hline Knowledge techniques & 20 & & & & \\
\hline Sampling/data integrity & 20 & 15 & 30 & 20 & 20 \\
\hline Sample representivity & 20 & & & & \\
\hline Sample accuracy & & 15 & & & \\
\hline Sampling programme & & 10 & 10 & 10 & 10 \\
\hline Estimation methodology & & 20 & 20 & 20 & 20 \\
\hline Definition of the geological model & 40 & & & & \\
\hline Other risk analysis techniques & & 40 & 50 & 50 & 50 \\
\hline \multicolumn{1}{|c|}{ Totals } & 100 & 100 & 110 & 100 & 100 \\
\hline
\end{tabular}

In Table I, the knowledge techniques relate to the application of appropriate methods, the sample (and data) integrity is associated with procedures, security issues, logging methods, positioning accuracy, etc. The sampling accuracy with respect to the grade scorecard relates to how the sample area and/or sample volume was measured.

The original De Beers classification committee determined that three of the five variables - geology, grade, and revenue - are critical and should be assigned the highest weighting (3). Volume was viewed as being slightly less important as it is a constructed representation of the geology, and was hence assigned a lower weighting (2), and density was assigned the lowest weighting (1). These weightings are applied to the relevant scorecard and a final average classification score calculated.

Classification limits were assigned as follows:

- $\quad$ 0-30 - Deposit (excluded from the resource)

- 30-70 - Inferred Mineral Resource

- 70-90 - Indicated Mineral Resource

- 90-100 - Measured Mineral Resource.

\section{External review}

The De Beers classification methodology calls for each classification to be independently reviewed prior to final sign-off by the CP. The external reviewer is given access to the MRCS and is required to comment on the answers and the scores but has no permission to change the original entries. The external reviewer documents appropriate comment and the Microsoft WordTM file is stored in the MRCS.

\section{Competent Person (CP)}

De Beers officially appoints a CP for each Anglo American reporting cycle (typically a year), and this person is responsible for mineral resource classification on a specific operation or project. The MRCS has been designed with this structure in mind, and represents a change from historical classifications, where the final responsibility rested with a classification committee.

In keeping with international reporting codes, the $\mathrm{CP}$ is ultimately accountable for the classification of mineral resources on an operation and must ensure that correct procedures have been followed during the classification process. The company letter of appointment, signed by the $\mathrm{CP}$ and the mine general manager, includes an abridged $\mathrm{CV}$ indicating the number of years of relevant experience that the $\mathrm{CP}$ has in terms of the type of deposit and style of mineralization. It includes proof of membership of a designated professional organization (e.g. SACNASP) and the letter is stored on the MRCS.

\section{The Mineral Resource Classification System (MRCS)}

The methodology has evolved through time, and recently significant changes have been made to the scorecard and the MRCS. For example, the ability to take cognisance of production history has been introduced as an accurate assessment of performance that shows the resource is performing as expected will result in reduced risk and therefore enhance the resource confidence. The software application has a number of attributes that simplify the classification process, namely, an SQL sequel database facility that stores a list of documents and information associated with the particular resource being classified, a help facility to explain the meaning of each question, and a user-friendly 'front end' that streamlines the process.

The MRCS includes a hierarchical structure that enables users to easily select (or create) the company, operation, resource, group, and classification. Permission to create a new company or operation is restricted but most users may create and edit a resource, group, or classification (Figure 3). Each of these operations is briefly explained below:

$>$ A Resource is named by the user and is defined by the geology (e.g. kimberlite, dyke, aeolian placer, beach placer, deep-water marine placer, fluvial placer,

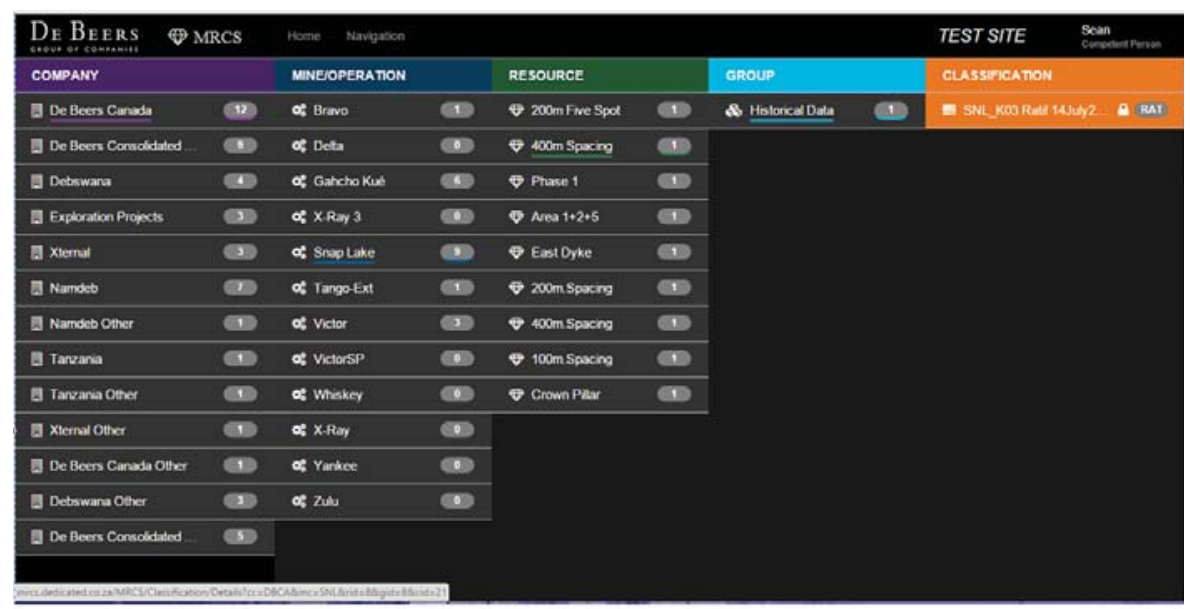

Figure 3-Example of the MRCS hierarchy showing a classification linked to a Group, a Resource, an operation, and a company 


\section{Development of a best-practice mineral resource classification system}

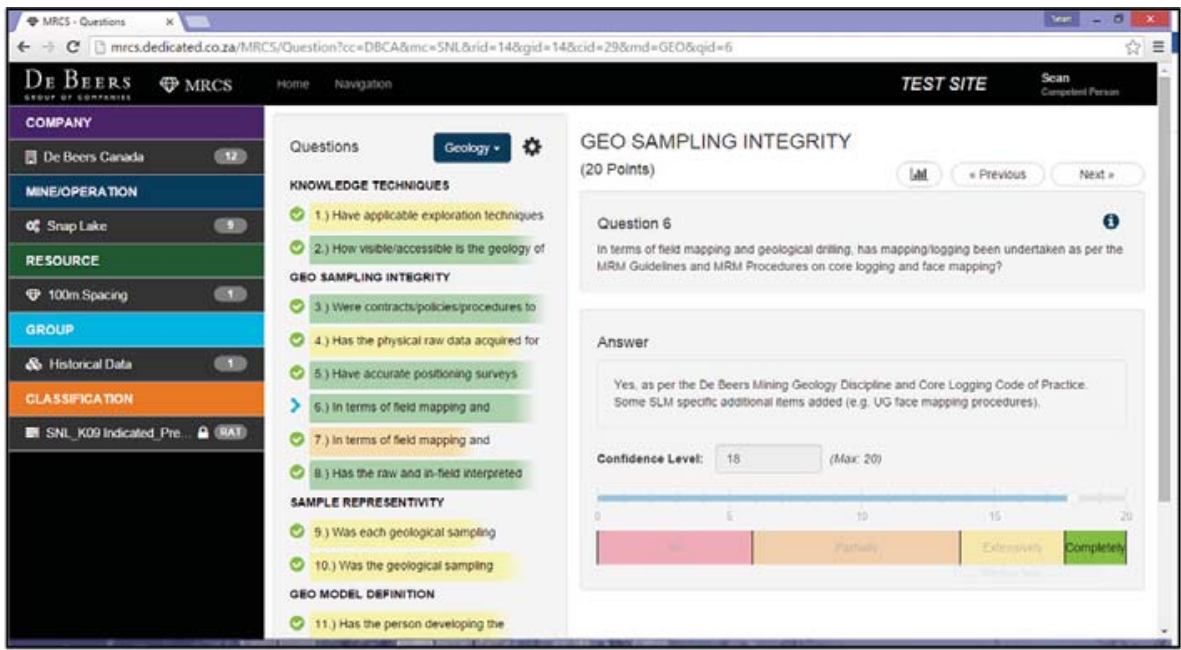

Figure 4-The geology scorecard of the De Beers Mineral Resource Classification System (MRCS)

shallow-water marine placer, tailings mineral resource, stockpile) and the deposit type (e.g. primary, secondary, tertiary)

$>$ A Group constitutes a user-defined group of classifications in a particular Resource, named by the user and including a brief description and spatial definition (e.g. a 'from-to' elevation in the case of a kimberlite)

> The Classification scorecard status could be preliminary, internally reviewed, externally reviewed, or ratified depending on how far the Mineral Resource has moved along the classification process.

Once the hierarchy has been appropriately defined, the classification scorecard is created and the user answers the questions appropriately based on his knowledge of the Mineral Resource (Figure 4). Hints are provided for uninitiated users as a guide to understanding the questions and comparative scoring functionality aids the user in selecting an appropriate score.

\section{Comparative statistics}

The De Beers classification method remains a subjective process, and therefore it is useful to provide a guideline related to how questions should be interpreted. To this end the MRCS includes functionality that enables the user to compare scores and answers from other classifications across the De Beers Group of companies. This is achieved by a selection process that enables the user to compare scores for a specific question, a group of questions on a scorecard, an entire scorecard, or the whole classification. This process is extremely useful, as De Beers has a vast array of diamond resources that have been classified, and enables new resources to be benchmarked. The comparative statistics module is user-friendly and provides rapid graphic solutions, as illustrated by the example in Figure 5. The upper portion of this figure shows a number of options for selecting classifications for the comparison, which include selection by company, mine, Resource, group, deposit type, and geology type.

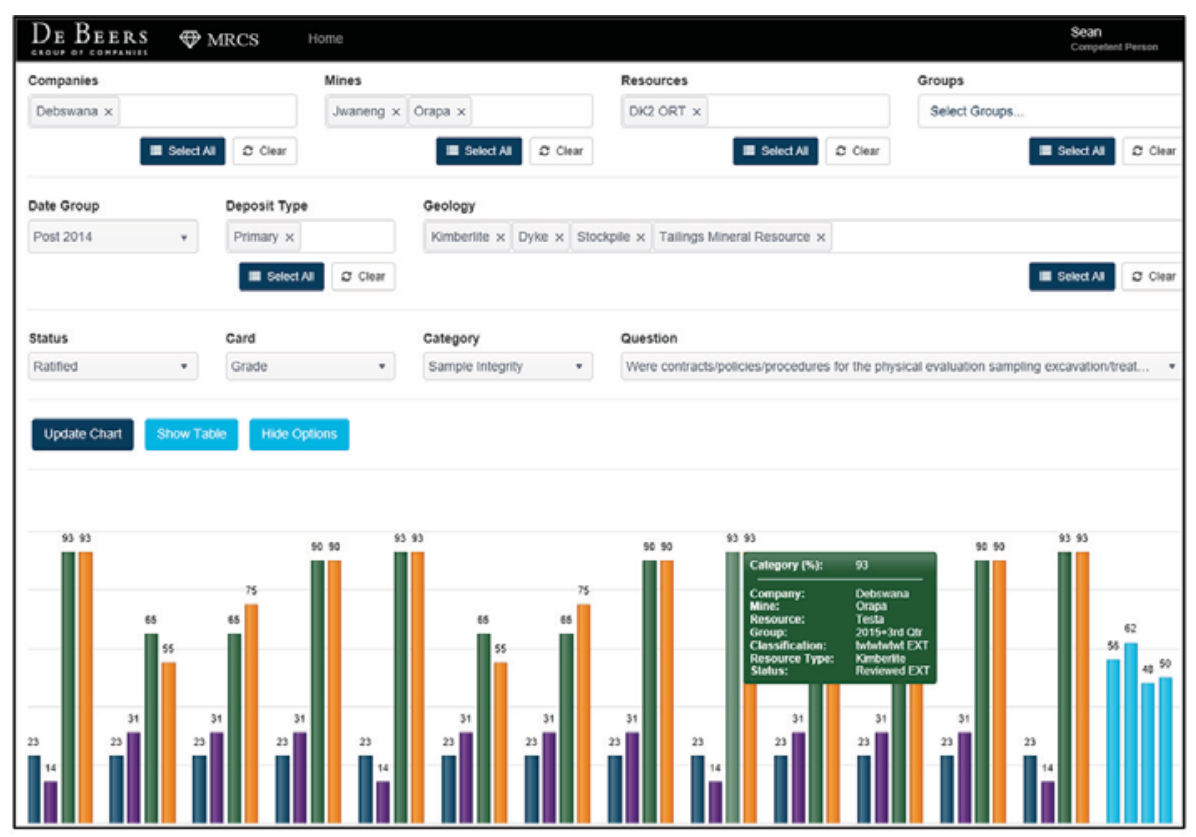

Figure 5-An example of the MRCS comparative statistics functionality 


\section{Development of a best-practice mineral resource classification system}

\section{Classification document management}

The MRCS includes a facility to store and manage documents associated with each classification. By way of example, it is important for users to have access to the documented sampling procedures, the geological models, the estimation reports, and review or audit documents. All versions of the classifications are stored, and therefore the MRCS document management component provides a record of the estimation process for each Mineral Resource, thereby creating an historical record for future users. Files of any format can be stored in the MRCS, e.g. ArcInfoTM files, WordTM documents, Gemcom ${ }^{\mathrm{TM}}$. Files, and ExcelTM spreadsheets.

\section{Mining performance}

In the latest MRCS, mining performance has been introduced as a method for assessing the level of confidence in a small part of the Resource close to existing production. This approach, documented by Noppé (2014) and others, is intended for a relatively small part of the Resource, for example the next two years of mining. By way of example, for a typical kimberlite Mineral Resource the performance documentation may include a model like the one illustrated schematically in Figure 6. In this example of a kimberlite mine a few benches have been included below the current mining level. The decision as to what is included is documented in the MRCS, e.g. three benches falling within the vertical variogram range. Should the business rules be met, the dark green portion shown in Figure 6 would be upgraded to an Indicated category.

In assessing confidence in this local resource the MRCS requires the user to answer a number of questions (all of which should be affirmative), including the following:

> Has face mapping, blast-hole chip sampling, field observations etc. been undertaken?

$>$ Is the change in geology insignificant in adjacent mining?

Is the orebody envelope changing insignificantly?

Do the density estimates correlate with geology?

Finally, as a measure of grade and value consistency, the following ratios are also considered:

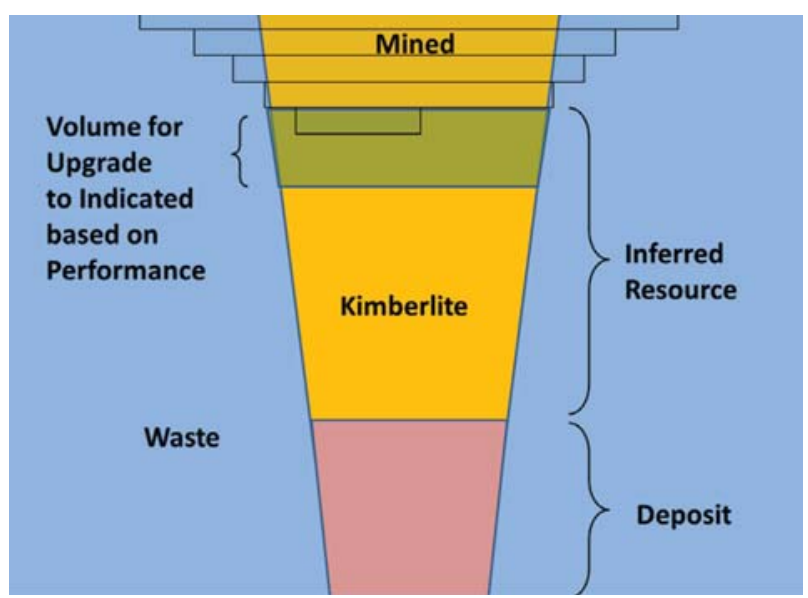

Figure 6-Schematic showing the application of performance assessment
$>$ RsCR: the average Resource carat ratio by year, defined as the carats expected from the Resource divided by the carats recovered

> RvCR: the average Reserve carat ratio by year, defined as the carats expected from the Resource after applying modifying factors divided by the carats recovered

$>$ Rv\$R: the average Reserve revenue ratio by year, defined as the value (in US dollars) expected from the Resource carats after applying modifying factors divided by the value of the carats recovered (in US dollars).

For an Indicated Mineral Resource, these ratios should meet the so-called 15\% rule (Cañas, 1995; Dohm, 2004; and others), meaning that the standard error of a given ratio measured over a period of one year should be $15 \%$ or less (90\% confidence limits).

\section{Conclusions}

The De Beers semi-quantitative approach to classification is robust and satisfies the key components of the international reporting codes, i.e. transparency, materiality, and competence. The classification method is not focused on specific estimation variables, such as kriging variance, but rather covers the five key criteria that combine to produce a diamond Mineral Resource estimate: geology, grade, volume, revenue and density. The classification approach is standardized and semi-quantitative and enables CPs on the operations to make informed decisions in terms of confidence. The comparative statistics is a powerful tool that allows classifications to be benchmarked against a large database of De Beers diamond Mineral Resources. The introduction of a performance module to incorporate information from mining is an important addition.

The MRCS is a user-friendly and flexible system and ensures that a robust record of the classification process on all De Beers operations is stored electronically. Importantly, the MRCS provides De Beers with a best-practice documented and justifiable classification for all types of deposits: kimberlites, placers, and tailings. Although the MRCS continues to change, the essence of the scorecard approach has been applied to successfully produce several hundred De Beers classifications.

\section{References}

CAÑAS, J.D. 1995. Salobo ore reserve model review. Letter from MRD (Mineral Resources Development Inc.) to Dr Alvaro Tohar (Anglo American Corp.), 30 July 1995.

Dонм, C.E. 2004. Quantifiable mineral resource classification: a logical approach. Proceedings of Geostatistics Banff 2004. Springer, Dordecht: pp. 399-341.

JORC. 2012. Australasian Joint Ore Reserves Committee. Australasian Code for Reporting of Exploration Results, Mineral Resources and Ore Reserves. The Joint Ore Reserves Committee of the Australasian Institute of Mining and Metallurgy, Australian Institute of Geoscientists, and Minerals Council of Australia. http://www.jorc.org/docs/JORC_code_2012.pdf

NopPÉ, M.A. 2014. Communicating confidence in Mineral Resources and Mineral Reserves. Journal of the Southern African Institute of Mining and Metallurgy, vol. 114. pp. 213-222.

SAMREC. 2009. South African Mineral Resource Committee. The South African Code for Reporting of Exploration Results, Mineral Resources and Mineral Reserves (the SAMREC Code). 2007 Edition as amended July 2009. http://www.samcode.co.za/downloads/SAMREC2009.pdf 